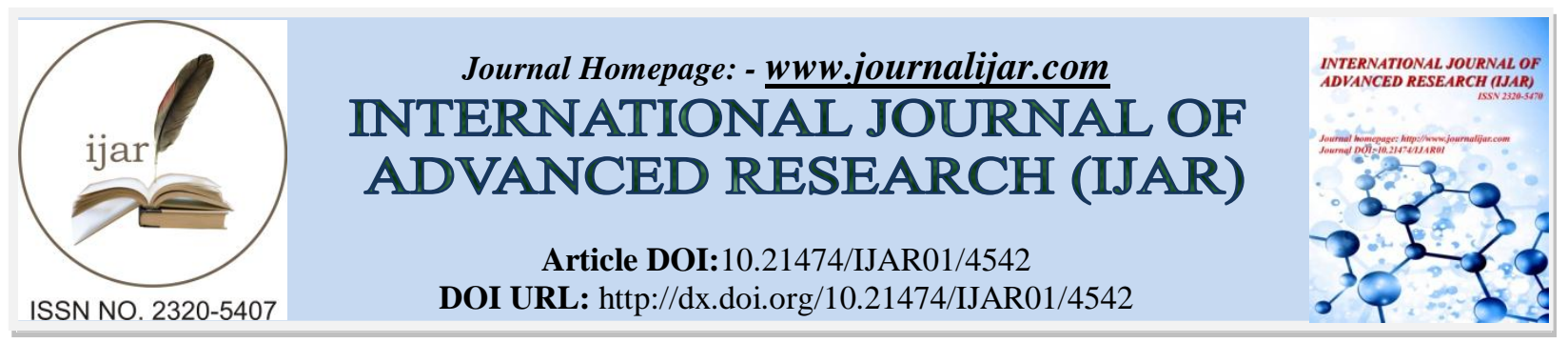

RESEARCH ARTICLE

\title{
NATURAL RUBBER BASED HYBRID NANOCOMPOSITE VIBRATION DAMPERS.
}

\author{
Ramzan Muhammad ${ }^{1}$ and Bimlesh Kumar ${ }^{2}$. \\ 1. MMAN Technical Campus, Malegaon, (M.S.), India. \\ 2. Sant Gajanan College of Engineering, Kolhapur (M.S.), India.
}

\section{Manuscript Info}

Manuscript History

Received: 20 April 2017

Final Accepted: 22 May 2017

Published: June 2017

Key words:-

Nanocomposite, frequency response, natural rubber, transient response, vibration damping

\section{Abstract}

In this study a novel natural rubber (NR) nanocomposite (Patent pending with IPC, India, File No. 1623/Mum/2014) is prepared by doping $\mathrm{Al}_{2} \mathrm{O}_{3}-\mathrm{ZrO}_{2}$ nanocomposite particles in NR matrix and characterized for the vibration damping properties. Nanocomposite rubber compounding ingredients, mixing procedure and curing parameters are clearly mentioned. The concentration of nanoparticles varies from $0-15$ phr (NP-0 to NP-15) of matrix NR. The crosslinking, surface morphology and dispersion of nanofillers in NR matrix can be clearly observed in SEM images. The performance of nanocomposite NR under impulsive excitation is assessed based on an experimental and numerical simulation approach, for frequencydomain and time-domain analysis. Nanocomposite NR is modeled as uniform beam with simply supported end conditions and transfer function in Laplace domain is derived. Frequency response, phase and root locus characteristics are plotted for theoretical modeling and validation of experimental results. The displacement amplitude attenuation, natural frequency, rise time and settling time all parameters are found to be a function of nanofiller concentration. The microstructural causes of energy dissipation in nanocomposite elastomer are discussed in detail. All parameters determined theoretically and experimentally, are in close agreement mutually and also with other researcher's results, which indicate that the new kind of nanocomposite NR is expected to be an effective damping material.

Copy Right, IJAR, 2017,. All rights reserved.

\section{Introduction:-}

Rubber is a naturally available unique material which is both elastic and viscous [1] and consists of innumerable microsized spring-mass dashpot systems which can provide excellent vibration damping effect under different loading and environmental conditions. In its original uncured form Natural Rubber (NR) is practically of limited use due to low strength, softening in hot environmental conditions and brittleness in cold weather [2, 3]. It strain crystallize upto certain extent but require reinforcement of fillers, such as carbon black [4, 5] and silica particles [6], to obtain the adequate static and dynamic characteristics. In certain studies the conventional reinforcing fillers, such as carbon black, used in bulk amounts in elastomer vulcanizates are replaced by a small amount of nanofillers to achieve a desirable combination of properties [7]. Rubber nanocomposites filled with layered silicates as well as nano calcium carbonate composite for various tire applications has been studied by Chandra and Bhandari [8]. The natural rubber nanocomposites with Cloisite $15 \mathrm{~A}^{\circledR}$, a commercial organoclay were prepared and characterized for 
their rheological, morphological, thermal and mechanical properties by Carli et al. [9]. The modal damping values of a composite beam through longitudinal, flexural, and torsional vibration responses were analyzed by short-time Fourier Transform (STFT) and Q-factor approximation methods by Yesilyurt and Gursoy [10]. Transfer function is a common parameter to evaluate the performance of the vibration control system; let it be active or passive. In passive vibration isolator design, higher damping is desirable at lower frequencies to reduce the resonance while low damping is required at higher frequencies to maximize the isolation [11].

For the products made of filled rubber compounds that operate under dynamic loads, such as the tire and air-spring [12] we still do not have a complete understanding of its mechanical behavior. The lack of published work in this regard limits its commercialization; hence a broad research horizon is present before the scholars. Reinforcement of nanocomposite fillers, as reported in this study, is still rare to find in the literature. $\mathrm{Al}_{2} \mathrm{O}_{3}-\mathrm{ZrO}_{2}$ nanocomposite particles exhibit optimum mechanical properties [13]; hence composite particles were synthesized for reinforcement instead of plain alumina or zirconia nanoparticles.

A comparative study is done between five samples of natural rubber reinforced with different concentration of Alumina $\left(\mathrm{Al}_{2} \mathrm{O}_{3}\right)$-Zirconia $\left(\mathrm{ZrO}_{2}\right)$ hybrid nanocomposite particles and a sample without reinforcement subjected to impulse excitation. Nanocomposite sample is modeled as simply supported beam subjected to impulse excitation and frequency response characteristics are derived in Laplace domain. Transient and frequency spectra are analyzed and the resonant magnitudes, corresponding frequencies, rise time and settling time experimentally and theoretically, are recorded and compared. The mathematical model of transfer function (tf) is simulated in MATLAB and frequency response and root locus characteristics are drawn for comparison. The results are found in close agreement and also validated through the results of previous researchers.

\section{Experimentation and Procedure:-}

Alumina-zirconia $\left(\mathrm{Al}_{2} \mathrm{O}_{3}-\mathrm{ZrO}_{2}\right)$ nanocomposite particles were synthesized through sol-gel processing route following the protocol as reported by Sarkar et al. [13].The details of nanocomposite particles synthesis and its characterization are not considered in this study. The natural rubber with highest purity (dust content $<0.04 \%$ ), ISNR-3L was obtained as per the specifications of Rubber Research Institute of India (RRII), Kottayam (India). The compounding and reinforcement of nanoparticles in NR is carried out on two-roll mill at 14 rpm roller speed and at ambient temperature with compounding ingredients in the same sequence as mentioned in the Table 1 . Curing and vulcanization is done by hot pressing in Collin molding press at $160^{\circ} \mathrm{C}$ and with 235 bar pressure. Five hybridnanocomposite rubber samples, reinforced with alumina-zirconia nanofillers, and one virgin rubber sample without nanofiller, were prepared in the form of square cross-sectional strips of dimension (L:W:D=150:150:2) mm with nanofiller concentrations varying from $0-15 \mathrm{phr}$ (NP-0, NP-5, NP-8, NP-10, NP-12, NP-15). The samples were cut in the dimension $(150 \times 30 \times 2) \mathrm{mm}$ and held as simply supported beam for vibration damping characterization. A schematic representation for the same is illustrated in the Fig. 1. An average impulsive force of $1 \mathrm{~N}$ is applied at the centre of the simply supported nanocomposite NR beam specimen and transient and frequency domain response is recorded by the sensor placed at a distance length/4 from left hand support.

SEM images of nanocomposite NR, illustrated in the Fig. 2. The mechanical properties, such as density ( $\rho$ ) and modulus (E), needed in the vibration damping characterization are determined as per the specifications IS-16082005 and ASTM-2240/DIN 53505 and tabulated in the Table 2. The damping factor $(\boldsymbol{\zeta})$ is determined by logarithmic decrement method from the transient response.

Table 1:- Compounding ingredients of Natural Rubber nanocomposite.

\begin{tabular}{|c|c|c|c|}
\hline $\begin{array}{c}\text { Sr. } \\
\text { No. }\end{array}$ & $\begin{array}{c}\text { Ingredients of Nanocomposite } \\
\text { Natural Rubber }\end{array}$ & Function & Quantity (phr) \\
\hline 1 & Natural Rubber (NR) & Matrix & 100 \\
\hline 2 & Zinc Oxide (ZnO) & Curing agent, Anticoagulant & 5.0 \\
\hline 3 & Stearic acid & Curing agent, accelerator, Anticoagulant & 2.0 \\
\hline 4 & $\mathrm{Al}_{2} \mathrm{O}_{3}-\mathrm{ZrO}_{2}$ Nanocomposite & Nanofillers & $0,5,8,10,12,15$ \\
\hline 5 & MBT & Accelerator & 1.5 \\
\hline 6 & MBTS & Accelerator & 1.0 \\
\hline 7 & Sulfur & Cross-linking and curing agent & 1.5 \\
\hline
\end{tabular}

MBT- Mercapto Benzothiazole MBTS- Mercapto Benzothiazole Disulphide 
Table 2:- Density, Modulus and Damping factor of nanocomposite NR with varying concentration of nanoparticles.

\begin{tabular}{|l|c|c|c|c|c|c|}
\hline Sample & NP-0 & NP-5 & NP-8 & NP-10 & NP-12 & NP-15 \\
\hline Density (kg/m $\mathbf{3})$ & 950 & 1000 & 1020 & 1035 & 1085 & 1110 \\
\hline Modulus (MPa) & 1.61 & 1.82 & 1.92 & 1.95 & 2.0 & 1.91 \\
\hline Damping factor $(\boldsymbol{\zeta )}$ & 0.0651 & 0.0663 & 0.0734 & 0.0749 & 0.0958 & 0.0913 \\
\hline
\end{tabular}

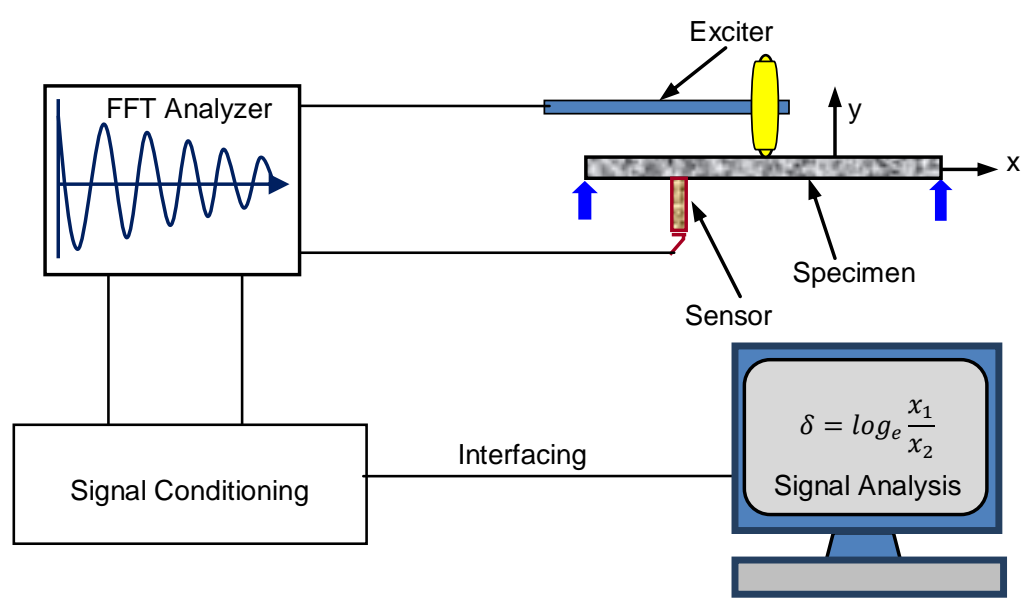

Fig. 1:- Schematic representation of experimental set-up.
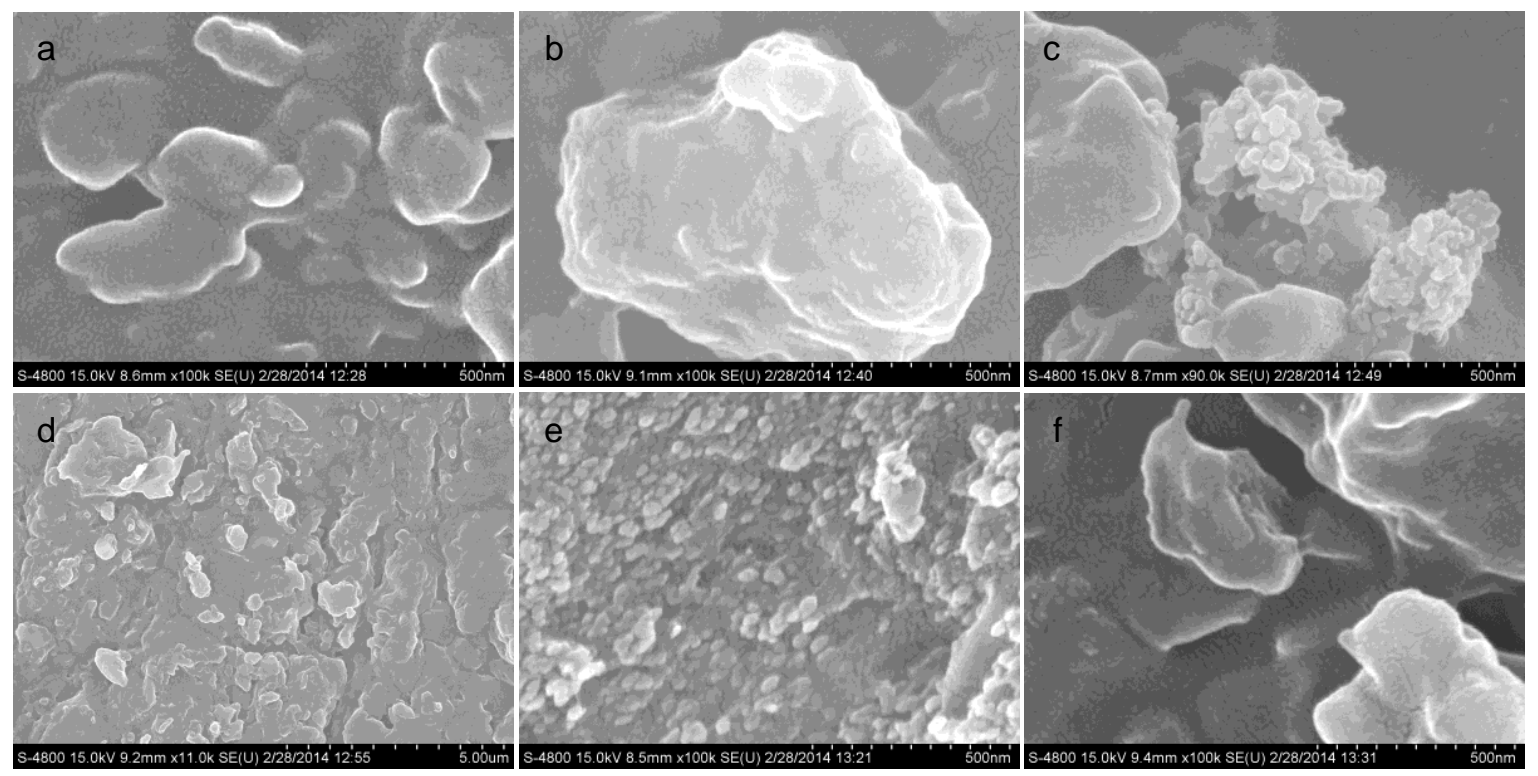

Fig. 2:- SEM images of nanocomposite NR; a) to f) NP-0, NP-5, NP-8, NP-10, NP-12 and NP-15 respectively

\section{Supporting Theory:-}

The dimensional parameters of simply supported nanocomposite NR beam are illustrated in the Fig. 3 .

For no load condition and without damping (undamped-free vibration) the equation of motion for a beam can be written as [14];

The Eq. (1) can be simplified as;

$$
E I \frac{\partial^{4} y}{\partial x^{4}}+\rho A \frac{\partial^{2} y}{\partial t^{2}}=0
$$

where;

$$
a^{2} \frac{\partial^{4} y}{\partial x^{4}}+\frac{\partial^{2} y}{\partial t^{2}}=0
$$




$$
a=\sqrt{\frac{E I}{\rho A}}
$$

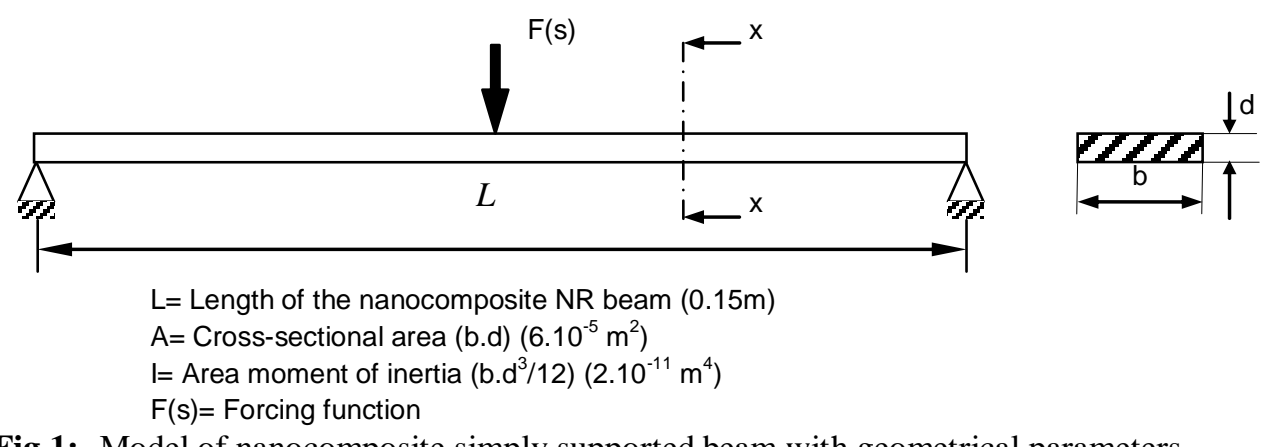

Fig.1:- Model of nanocomposite simply supported beam with geometrical parameters.

The solution of the Eq. (1) can be obtained as;

$$
y(x, t)=A \cosh \beta x+B \sinh \beta x+C \cos \beta x+D \sin \beta x
$$

where $\mathrm{A}, \mathrm{B}, \mathrm{C}$ and $\mathrm{D}$ are constants and can be determined from the boundary conditions.

$\beta=$ Eigenvalues corresponding to the specific boundary conditions; $\beta=n \pi / L ;(n=1$ to $\infty)$

$\mathrm{y}=$ Eigenfunction for undamped free vibration

Considering nanocomposite (visco-elastic) beam subjected to external loading $(F)$, which is a case of beam under forced-damped vibration. The modified equation of motion including the damping constant $(c)$ can be obtained as;

$$
E I \frac{\partial^{4} y}{\partial x^{4}}+\rho A \frac{\partial^{2} y}{\partial t^{2}}+c \frac{\partial y}{\partial t}=F
$$

Applying the boundary conditions of simply supported beam to Eq. (4);

$$
\begin{array}{lll}
\text { At } x=0 ; & y(0, \mathrm{t})=0 & {\left[\frac{\partial^{2} y}{\partial t^{2}}\right]_{x=0}=0} \\
\text { At } x=\mathrm{L} ; & y(\mathrm{~L}, \mathrm{t})=0 & {\left[\frac{\partial^{2} y}{\partial t^{2}}\right]_{x=L}=0}
\end{array}
$$

Constants A, B and C are zero and the solution of Eq. (4) is given by;

$$
y(x, t)=\sum_{n=1}^{\infty} D_{n} \sin \left(\frac{n \pi}{L}\right) x
$$

The relation between the eigenvalues and the corresponding natural frequencies is given by;

$$
\omega_{n}=\beta^{2} \sqrt{\frac{E I}{\rho A}}
$$

The natural frequencies and the respective mode shapes are calculated by using Eqs. (7) and (6) respectively. The damping ratio $(\zeta)$ can be specified as;

$$
\zeta=\frac{c}{2 m \omega_{n}}
$$

From the above equations the Eq. (5) can be modified as;

$$
\ddot{y}_{l}+2 \omega_{n i} \zeta_{i} \dot{y}_{i}+\omega_{n i}^{2} y_{i}=\frac{1}{\mu} F \quad(i=1,2,3 \ldots)
$$

where;

$$
\rho A=\mu
$$
$\mu=$ Mass per unit length

Laplace transform of the equation (10) with initial condition $\mathrm{y}(0)=0$ and $\dot{y}(0)=0$ will give;

$$
\begin{gathered}
\mathcal{L}\{\ddot{y}(t)\}=s^{2} y(s) \\
s^{2} y(s)+2 \omega_{n} \zeta s y(s)+\omega_{n}^{2} y(s)=\frac{1}{\mu} F(s)
\end{gathered}
$$

where;

$$
s=j \omega
$$

The transfer function $\mathrm{H}(\mathrm{s})$ is given by;

Frequency response of the system is given by;

$$
\begin{array}{r}
H(s)=\frac{y(s)}{F(s)} \\
H(s)=\frac{1 / \mu}{s^{2}+2 \omega_{n} \zeta s+\omega_{n}^{2}}
\end{array}
$$

$$
H(j \omega)=\frac{1 / \mu}{(j \omega)^{2}+2 \omega_{n} \zeta(j \omega)+\omega_{n}^{2}}
$$


Let $r=$ Frequency ratio

$$
\begin{gathered}
H(j \omega)=\frac{1 / \mu}{-\omega^{2}+2 \omega \omega_{n} \zeta j+\omega_{n}^{2}} \\
r=\frac{\omega}{\omega_{n}} \\
H(j \omega)=\frac{1 / \mu \omega_{n}^{2}}{\left[1-r^{2}\right]+j(2 \zeta r)}
\end{gathered}
$$

\section{Results and Analysis:-}

Frequency domain response for impulse input:-

The frequency domain response of the displacement magnitude in microns $(\mu \mathrm{m})$ of all samples is as shown in Fig. 4. The measurement results of the peak values of displacement in frequency domain, shown in Table 3, indicate the total energy level of the responses in the respective frequency range. The overall behavior of the system is accurately represented by these spectra. Natural frequency of virgin NR (NP-0) is $10.5 \mathrm{~Hz}$ whereas that with $15 \mathrm{phr}$ of $\mathrm{Al}_{2} \mathrm{O}_{3}-\mathrm{ZrO}_{2}$ reinforcement (NP-15) is $11.56 \mathrm{~Hz}$ which is an increase of $9.17 \%$; however maximum frequency at resonant amplitude is recorded for NP-12 as $13.19 \mathrm{~Hz}$ which is an increase of $20.39 \%$.

A little concentration on the frequency response spectra in Fig. 4 can illustrate that the number of peaks or nonlinearity of response is more above $20 \mathrm{~Hz}$ for nanofiller loading above $8 \mathrm{phr}$. The probable cause is the inertia effect of small cluster of metallic nanoparticles, which are closely oriented at higher concentrations, after the threshold of energy at resonant peak.
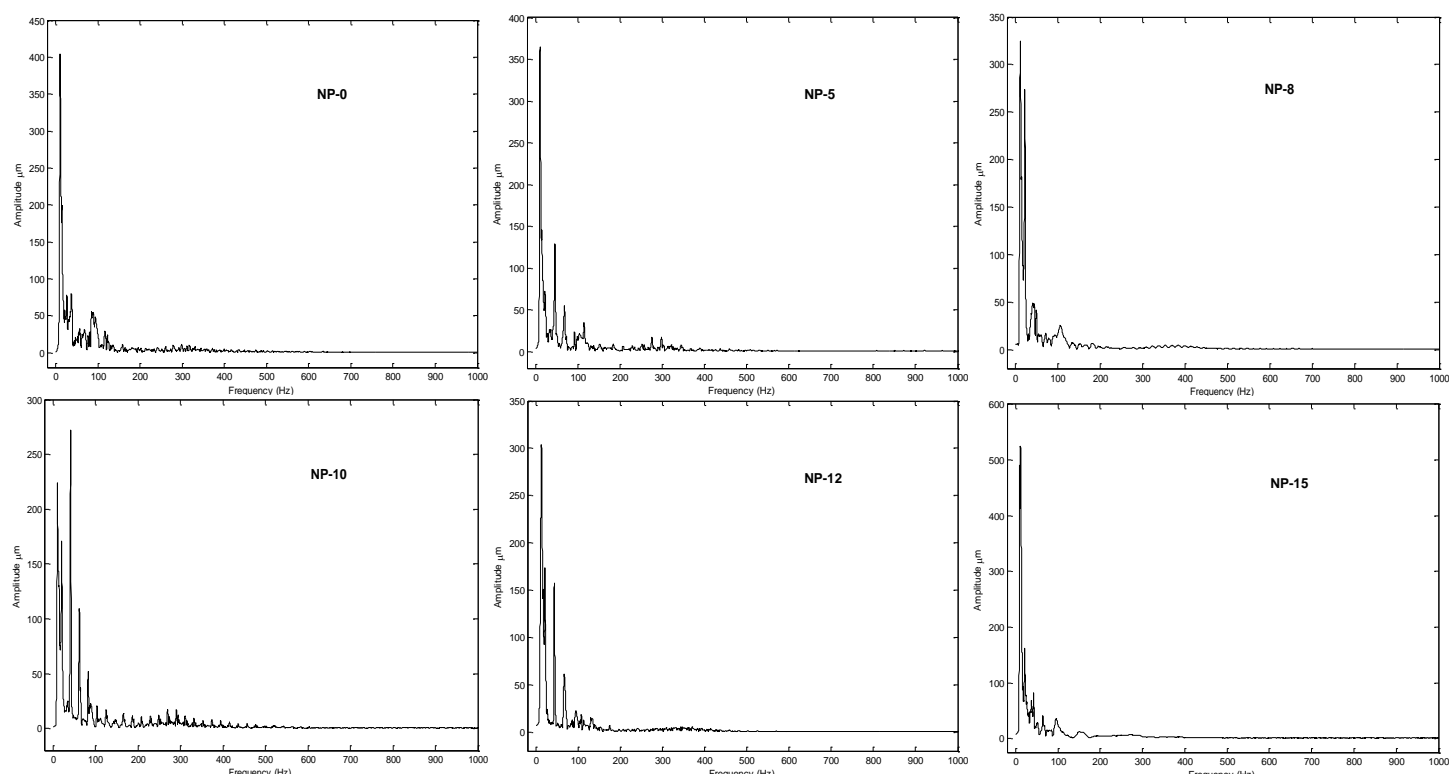

Fig.2:- Frequency domain response of nanocomposite samples for impulse excitation.

Table 3:- The resonant amplitude, $\%$ attenuation, respective resonant frequency and $\%$ increases in $\omega_{\mathrm{n}}$

\begin{tabular}{|c|c|c|c|c|c|}
\hline $\begin{array}{c}\text { Sr. } \\
\text { No. }\end{array}$ & Sample & $\begin{array}{c}\text { Resonant } \\
\text { Amplitude }(\boldsymbol{\mu m})\end{array}$ & $\begin{array}{c}\text { \% Amplitude } \\
\text { attenuation w.r.t. } \\
\text { NP-0 }\end{array}$ & $\begin{array}{c}\text { Resonant } \\
\text { Frequency } \boldsymbol{\omega}_{\mathbf{n}}(\mathbf{H z})\end{array}$ & $\begin{array}{c}\text { \% increase in } \boldsymbol{\omega}_{\mathbf{n}} \\
\text { w.r.t. NP-0 }\end{array}$ \\
\hline 1 & NP-0 & 403.7 & ---- & 10.50 & ---- \\
\hline 2 & NP-5 & 365.1 & 9.56 & 10.44 & -0.57 \\
\hline 3 & NP-8 & 324.2 & 19.69 & 11.38 & 7.73 \\
\hline 4 & NP-10 & 271.8 & 32.67 & 10.56 & 0.57 \\
\hline 5 & NP-12 & 303.3 & 24.87 & 13.19 & 20.39 \\
\hline 6 & NP-15 & 524.1 & -29.82 & 11.56 & 9.17 \\
\hline
\end{tabular}

Transfer Function (tf) and Phase $(\varphi)$ :-

The natural frequency of fundamental mode for each sample is calculated by the Eq. (7) for theoretical analysis. The above Eq. (13) is plotted in the Fig. 5with respect to the damping factor $(\zeta)$ and natural frequency of fundamental 
mode and the measurements are illustrated in the Table 4. Figure 6 represent the corresponding phase lag with respect to the frequency ratio. The following observations can be made from these results; (i) at zero frequency (static loading) the tf for all samples are approximately same, (ii) peak amplitude occurs little left of resonance, (iii) tf decreases as nanofiller loading increases and (iv) above resonance tf is negative and at very high frequencies it is approximately zero. Besides this trend is exactly matching to that of the experimental spectra, these points are justified in the following lines.

At zero frequency (well below resonance); $\omega_{n}^{2} \gg \omega \omega_{n} \gg \omega^{2}$ refer Eq. (12);

$$
\begin{gathered}
H(j \omega) \cong \frac{1 / \mu}{\omega_{n}^{2}} \\
H(j \omega)=\frac{1}{\mu \omega_{n}^{2}}
\end{gathered}
$$

Hence magnitude (Gain) and phase are given by respectively;

$$
\begin{gathered}
\left|\frac{y(j \omega)}{F(j \omega)}\right|=\frac{1}{\mu \omega_{n}^{2}} \\
\angle \frac{y(j \omega)}{F(j \omega)}=0
\end{gathered}
$$

At zero frequency the damping effect of the system is negligible as indicated by Eq. (14); hence the tf remains unaffected for all samples. Though all values are not exactly same but vary between 330 counts for NP-0 to 280 counts for NP-15, which is about $6 \%$ of smallest peak value (842.7 counts) and can be neglected. This variation is due to the difference in the natural frequency of fundamental mode of the samples. Theoretically the peak amplitude occurs at $+/-1 / \sqrt{2}$ from the resonance depending upon the nature of vibration and unbalance, the deviation in the spectra at either side of resonance is recorded.

At resonance; $\omega=\omega_{n}$;

$$
\begin{aligned}
H(j \omega) & =\frac{y(j \omega)}{F(j \omega)}=\frac{1 / \mu}{2 j \zeta \omega_{n}^{2}} \\
& =\frac{1}{2 \mu j \zeta \omega_{n}^{2}}
\end{aligned}
$$

Hence magnitude (Gain) and phase are given by respectively;

$$
\begin{gathered}
\left|\frac{y(j \omega)}{F(j \omega)}\right|=\left|\frac{-j / \mu \omega_{n}^{2}}{2 \zeta}\right|=\frac{1}{2 \mu \zeta \omega^{2}} \\
\angle \frac{y(j \omega)}{F(j \omega)}=-90
\end{gathered}
$$

Equation (15) illustrates that the damping plays a crucial role at resonant frequency. The peak amplitude is a function of damping factor $(\zeta)$, which depends on nanofiller concentration. The damping effect is improved for higher concentration. In the magnified frame of the Fig. 5, it is observed that the peak amplitude shifts away from the resonant frequency ratio for higher filler concentration, the exact values of which are recorded in the Table 4 . As $r=\omega / \omega_{n}$, the reduction in $r$ is due to increase in natural frequency, as recorded also in experimental results.

At higher frequency (above resonance); $\omega^{2} \gg \omega \omega_{n} \gg \omega_{n}^{2}$;

$$
\begin{aligned}
& H(j \omega) \cong \frac{1 / \mu}{-\omega^{2}} \\
& H(j \omega)=\frac{-1}{\mu \omega^{2}}
\end{aligned}
$$

Hence magnitude (Gain) and phase are given by respectively;

$$
\begin{gathered}
\left|\frac{y(j \omega)}{F(j \omega)}\right|=\left|\frac{-1}{\mu \omega^{2}}\right|=\frac{1}{\mu \omega^{2}} \\
\angle \frac{y(j \omega)}{F(j \omega)}=-180
\end{gathered}
$$

Since tf has two components, real and imaginary; hence it can be negative. At very high frequencies damping effects are not significant but stiffness and inertia plays an important role in vibration attenuation, due to which tf reaches closer to zero as illustrated by the Eq. (16).

The phase angle $(\varphi)$ is plotted in Fig. 6 and relative position of each sample before and after resonance is shown in magnified frames. It follows the trend of single degree of freedom system in which the phase lags below resonance and leads above resonance with increasing $\zeta$. 
Table 4:- Theoretical values of resonant amplitudes and corresponding variation in frequency ratio

\begin{tabular}{|c|c|c|c|c|c|}
\hline $\begin{array}{c}\text { Sr. } \\
\text { No. }\end{array}$ & Sample & $\begin{array}{c}\text { Resonant } \\
\text { Amplitude (dB) }\end{array}$ & $\begin{array}{c}\text { \% Amplitude attenuation } \\
\text { w.r.t. NP-0 }\end{array}$ & $\begin{array}{c}\text { Resonant } \\
\text { Frequency ratio } \boldsymbol{r}\end{array}$ & $\begin{array}{c}\text { \% Reduction in } \\
\text { resonant } \boldsymbol{r} \text { w.r.t. } \\
\text { NP-0 }\end{array}$ \\
\hline 1 & NP-0 & 1319 & ---- & 0.93 & --- \\
\hline 2 & NP-5 & 1327 & -0.61 & 0.93 & 0 \\
\hline 3 & NP-8 & 1220 & 7.51 & 0.92 & 1.08 \\
\hline 4 & NP-10 & 1188 & 9.93 & 0.92 & 1.08 \\
\hline 5 & NP-12 & 885.8 & 32.84 & 0.9 & 3.23 \\
\hline 6 & NP-15 & 842.7 & 36.11 & 0.91 & 2.15 \\
\hline
\end{tabular}

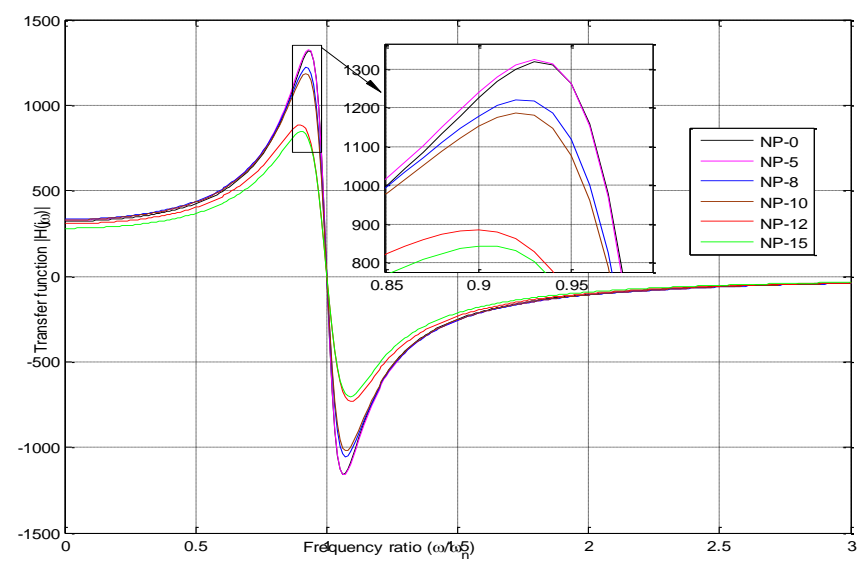

Fig.3:- Transfer function corresponding to the fundamental mode of vibration.

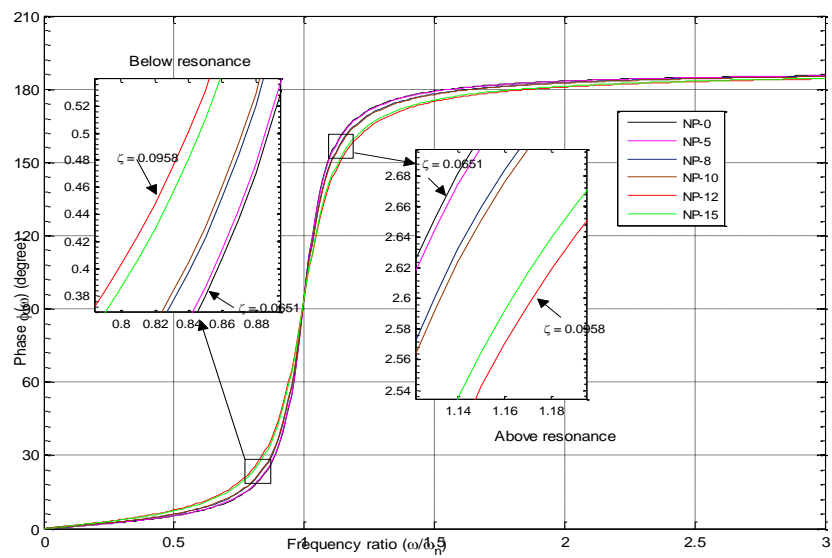

Fig.4:-. Phase lag of the nanocomposite NR

Transient Response for Impulse Input:-

Transient history of the nanocomposite NR samples as illustrated in the Fig. 7. The amplitude decay time decreases due to increasing damping effect caused by more filler concentration. The least time required for amplitude decay is noted for NP-12 as 0.3035 second, which is $64.43 \%$ less as compared to that of NP-0. This result is in complete agreement with frequency domain response analysis and also with the similar trend in both cases for varying concentration of the nanofillers in the samples.

Table 5:- Transient response, sensitivity and reduction in amplitude decay time for fundamental mode.

\begin{tabular}{|c|c|c|c|c|c|c|}
\hline $\begin{array}{l}\text { Sr. } \\
\text { No. }\end{array}$ & Sample & $\begin{array}{c}\text { Rise time } \\
\mathbf{t}_{1}(\mathrm{Sec})\end{array}$ & $\begin{array}{c}\% \text { Reduction } \\
\text { in } \mathrm{t}_{1}\end{array}$ & $\begin{array}{c}\text { Amplitude decay } \\
\text { time } t_{2}(\mathrm{Sec})\end{array}$ & $\begin{array}{l}\text { Settling time } \\
\Delta t=t_{2}-t_{1}\end{array}$ & $\begin{array}{c}\text { \% Reduction in } \\
\Delta t\end{array}$ \\
\hline 1 & NP-0 & 0.1370 & ---- & 0.9902 & 0.8532 & ---- \\
\hline 2 & NP-5 & 0.1289 & 5.91 & 0.4888 & 0.3599 & 57.82 \\
\hline 3 & NP-8 & 0.1313 & 4.16 & 0.4446 & 0.3133 & 63.28 \\
\hline
\end{tabular}




\begin{tabular}{|l|c|c|c|c|c|c|}
\hline 4 & NP-10 & 0.1260 & 8.03 & 0.5706 & 0.4446 & 47.89 \\
\hline 5 & NP-12 & 0.1025 & 25.18 & 0.4060 & 0.3035 & 64.43 \\
\hline 6 & NP-15 & 0.1199 & 12.48 & 0.5913 & 0.4714 & 44.75 \\
\hline
\end{tabular}
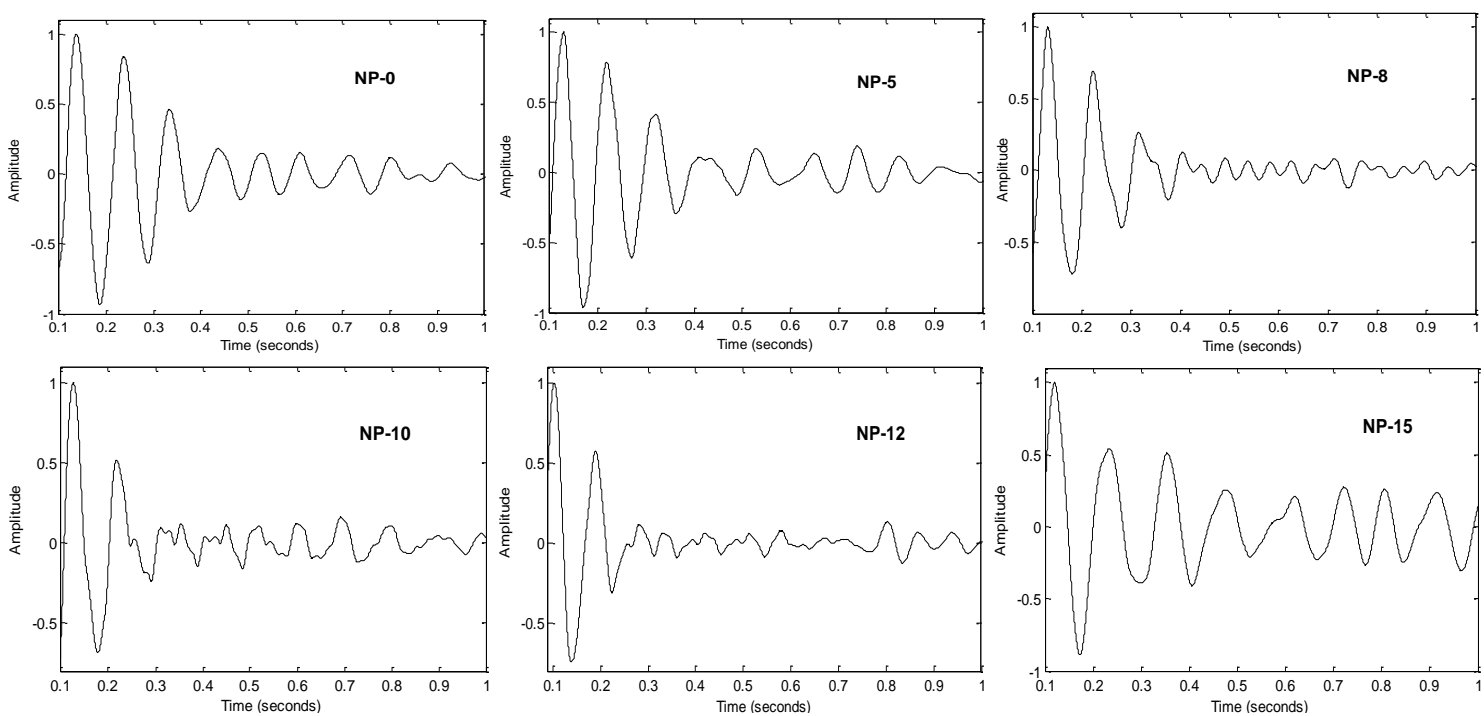

Fig.5:- Transient response of nanocomposite NR samples for impulse excitation.

\section{Root locus Analysis:-}

The root locus of transfer function from the Eq. (12) is plotted for transient analysis in Fig. 8 which illustrates that all poles are located in the left half of the plane showing the stability of the system. It can be noted from the Table 6 that all roots are negative real and complex which indicates the stability and oscillation of the system. These roots indicate decaying oscillations and more negativity of the poles indicates much faster decaying. The location of poles for NR nanocomposite dampers is a function of nanofiller concentration with their damping ratio. The natural frequency is highest for NP-10 as $28.4 \mathrm{rad} \mathrm{s}^{-1}$ and the gain is non-zero. However the least overshoot is represented by NP-12 as $73.9 \%$ and largest negative root as -2.69 , which indicate most rapid decaying of the amplitude.

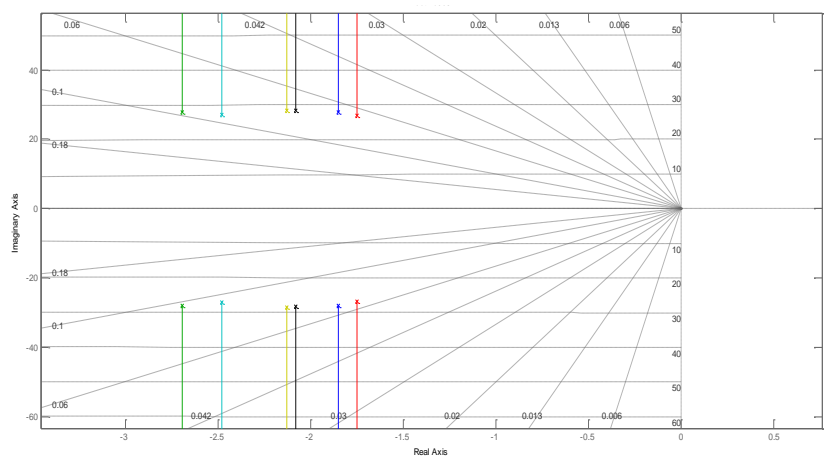

Fig.6:- Root locus graph to check the stability of the system

Table 6:-. Analysis of root locus graph.

\begin{tabular}{|c|c|c|c|c|c|}
\hline Sample & Damping factor $(\boldsymbol{\zeta})$ & Frequency $\left(\mathbf{r a d ~ s e c}^{-\mathbf{1}}\right)$ & Gain & Overshoot $(\%)$ & Poles \\
\hline NP-0 & 0.0651 & 26.9 & 0 & 81.5 & $-1.75-26.8 \mathrm{i}$ \\
\hline NP-5 & 0.0663 & 27.9 & 0 & 81.2 & $-1.85-27.8 \mathrm{i}$ \\
\hline NP-8 & 0.0734 & 28.3 & 0 & 79.4 & $-2.08-28.3 \mathrm{i}$ \\
\hline NP-10 & 0.0749 & 28.4 & 0.0261 & 79.0 & $-2.13-28.3 \mathrm{i}$ \\
\hline NP-12 & 0.0958 & 28.1 & 0 & 73.9 & $-2.69-28 \mathrm{i}$ \\
\hline NP-15 & 0.0913 & 27.1 & 0 & 75.0 & $-2.48-27 \mathrm{i}$ \\
\hline
\end{tabular}




\section{Discussion and Validation:-}

The ability of the rubber molecular chains to form nano or microscale-diameter spheres around individual nanoparticles or small cluster of nanoparticles favors the formation of a strong bond with the rubber matrix [15]. Size of reinforced nanoparticles may vary from 1 to $100 \mathrm{~nm}$ in diameter and/or length and these nanoparticles can accommodate in the voids at favorable geometric orientations of the molecular structure of rubber.

The rise in damping and stiffness effects in the nanocomposite rubber is predicted through three micromechanisms; (i) elastomeric matrix, (ii) matrix nanofiller interaction and (iii) stick-slip motion between nanoparticles themselves. All three mechanisms are further divided into two components each; first energy dissipation mechanism and the second energy storing mechanism, commonly indicated by loss modulus and storage modulus respectively. The energy loss in later two cases is coulomb damping, which takes place due to sliding friction, whereas in former case it is viscous damping caused by elastomeric molecular chains. The energy storing medium is elasticity in all cases. At low frequency the time for entanglement and disentanglement of elastomeric chains, similarly the slipping time for nanoparticles is sufficient, all six mechanisms are active; hence the damping effect is dominating and the amplitude attenuation is distinctly observed at resonance. Conversely, at high frequency the time is very short for the micro damping mechanisms to be activated; hence damping does not play any significant role and the vibrational energy is stored in only elastic components of all three mechanisms.

Some scholars have justified that when damping effect increases through the stiffness variation of isolator or damper, the resonant frequency shifts towards larger values [16, 17]. An increase in isolator natural frequency by about $18 \%$ corresponds to a $40 \%$ increase in stiffness; hence for the nanocomposite NR system the improvement in stiffness is about $55 \%$.

The transient response of a control system is measured by percent overshoot, which is indirectly the measure of its stiffness and damping factor $(\zeta)$. Least percent overshoot is desirable which indicate the amplitude decay in shortest time. The sensitivity and rise time of a damping system is controlled by stiffness whereas the settling time is a function of damping factor. Hence in an ideal damping system, the stiffness and damping both should be balanced. The most interesting aspect and novelty of this study is simultaneous improvement in damping factor and stiffness by about $32.05 \%$ and $55 \%$ respectively.

\section{Conclusion:-}

The NR- $\mathrm{Al}_{2} \mathrm{O}_{3}-\mathrm{ZrO}_{2}$ hybrid nanocomposite samples were successfully prepared by two roll mill followed by hot pressing process. The results describe the improvement in the viscoelastic properties of natural rubber nanocomposite as a function of its nanostructure. The natural frequency as a function of stiffness is found increasing with nanofiller concentration. From the above discussion, as essence of the study, it can be finally concluded that 12 phr alumina-zirconia nanocomposite particles concentration in NR is optimum which can excellently enhance its dynamic characteristics without affecting viscous properties and the new kind of nanocomposite rubber is expected to be an effective isolator material.

\section{Acknowledgement:-}

The authors gratefully acknowledge the lab facility provided by Polycab Wires Pvt. Ltd. Halol (India) and the instrumentation facility provided by UICT, NMU, Jalgaon for SEM.

There is no specific grant from any funding agency in the public, commercial, or not-for-profit sectors.

\section{References:-}

1. R.J. Schaefer, C.M. Harris, A.G. Piersol, Harris' Shock and Vibration Handbook, $5^{\text {th }}$ Edition McGraw-Hill Handbooks, New York, 2002.

2. J.A. Brydson, Rubber chemistry, Springer, London, 1978.

3. A.S. Aprem, K. Joseph, S. Thomas, Recent developments in the crosslinking of elastomers. Rubber Chemistry and Technology 78 (2005) 458-488.

4. A.E. Job, F.A. Oliveira, N. Alves, , J.A. Giacometti, L.H.C. Mattoso, Conductive composites of natural rubber and carbon black for pressure sensors. Synthetic metals 135 (2003) 99-100.

5. Y.H. Zhan, G.Q. Liu, H.S. Xia, N. Yan, Natural rubber/carbon black/carbon nanotubes composites prepared through ultrasonic assisted latex mixing process. Plastics, Rubber and Composites 40 (2011) 32-39. 
6. S. Prasertsri, N. Rattanasom, Mechanical and damping properties of silica/natural rubber composites prepared from latex system. Polymer Testing30 (2011) 515-526.

7. A. Das, K.W. Stöckelhuber, R. Jurk, D. Jehnichen, G. Heinrich, A general approach to rubbermontmorillonitenanocomposites: Intercalation of stearic acid. Applied clay science 51(2011) 117-125.

8. A.K. Chandra, V. Bhandari, Nanocomposites for Tyre Applications, in:Visakh PM et al. (Eds.), Advances in Elastomers II, Advanced Structured Materials, Heidelberg, Berlin, 2013, pp. 183-203. (DOI: 10.1007/978-3642-20928-4_6)

9. L. N. Carli, C.R. Roncato, A. Zanchet, R.S. Mauler, M. Giovanela, R.N. Brandalise, J.S. Crespo, Characterization of natural rubber nanocomposites filled with organoclay as a substitute for silica obtained by the conventional two-roll mill method. Applied Clay Science 52 (2011) 56-61.

10. I. Yesilyurt, H. Gursoy, Estimation of elastic and modal parameters in composites using vibration analysis. Journal of Vibration and Control (2013) 1-16. (DOI: 10.1177/1077546313486275)

11. A. Preumont, Vibration Control of Active Structures: An Introduction (Vol. 179) Springer 2011.

12. M. Liu, M.S. HooFatt, A constitutive equation for filled rubber under cyclic loading, International. Journal of Non-Linear Mechanics 46 (2011) 446-456.

13. D. Sarkar, S. Adak, N.K. Mitra, Preparation and characterization of an $\mathrm{Al}_{2} \mathrm{O}_{3}-\mathrm{ZrO}_{2}$ nanocomposite, Part I: Powder synthesis and transformation behavior during fracture. Composites A: Applied Science and Manufacturing 38 (2007) 124-131.

14. L. Meirovitch, Fundamentals of Vibrations, McGraw-Hill International edition, Singapore, 2001.

15. A.H. Barber, E. Wiesel, H.D. Wagner, Crack deflection at a transcrystalline junction. Composites Science and Technology 62 (2002) 1957-1964.

16. H. Du, W. Li, N. Zhang, Semi-active variable stiffness vibration control of vehicle seat suspension using an MR elastomer isolator. Smart Materials and Structures 20 (2011) 105003.

17. G.J. Liao, X.L. Gong, S.H. Xuan, C.J. Kang, L.H. Zong, Development of a real-time tunable stiffness and damping vibration isolator based on magnetorheological elastomer. Journal of Intelligent Material Systems and Structures 23 (2012) 25-33. 